\title{
Toward Understanding The Role Of Web 2.0 Technology In Self-Directed Learning And Job Performance
}

\author{
Shirley J. Caruso, Northeastern Illinois University, USA
}

\begin{abstract}
This paper serves as an exploration and thick description of job performance outcomes based upon the manner in which self-directed learning activities of employees are conducted, mediated by the use of Web 2.0 technologies in organizational settings. It provides a collective view of the role that Web 2.0 technology plays in self-directed workplace learning and job performance outcomes to benefit employees, organizations, and human resource development professionals. To expand further the knowledge base of adult learning and self-directed learning activities, this paper places its focus on the role of Web 2.0 technology in adult learners' engagement in self-directed learning. Part of the discussion focuses on learners' preferences in relation to the emergence of Web 2.0 technology. This discussion of learner preferences explores learning environments that participants engaged in and the motivation behind their engagement. This paper contributes to the field of human resource development by providing a new lens that views the role of Web 2.0 technology in self-directed learning and job performance within an organizational setting, thereby enabling its integration into a blended-learning site. A practical application resulting from this paper is to provide insight to human resource development professionals into best practices and recommendations for the adoption and application of Web 2.0 technology.
\end{abstract}

Keywords: Self-Directed Learning; Web 2.0 Technologies; Job Performance Outcomes; Human Resource Development

\section{INTRODUCTION}

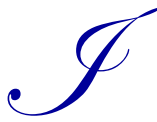

$\mathrm{n}$ today's workplace, employees have access to incessant self-directed learning opportunities through the use of Web 2.0 technology (Boileau, 2011). Web 2.0 is a term that describes the changing developments in the use of World Wide Web technology and Web design that aims to enhance creativity, procure information sharing, increase collaboration, and improve the functionality of the Web as we know it (Web 1.0; Stern, 2015). These changes have led to the development and evolution of Web 2.0 technology (Boileau, 2011; Stern, 2015). Examples of Web 2.0 technology include Web-based communities and hosted services, such as social-networking sites (e.g., Facebook), video sharing sites (e.g., YouTube), wikis, blogs, performance support tools, performance support systems, and search engines such as Bing, Yahoo, and Google.

\section{Performance Support and Self-Directed Learning}

Web 2.0 technologies are quickly moving from providing static information and facilitating transaction to performance support that is a more interactive, personable, and social experience (Reiser \& Dempsey, 2012). Performance support is a tool, system, or other resource, ranging from print to technology support, which provides just the right amount of task guidance, support, and productivity benefits to the user, precisely at the moment of need (Rosenberg, 2013). Consequently, employees have access to Web 2.0 technology at their disposal (i.e., videos, podcasts, blogs, and wikis, as well as Web conferencing and social networking sites such as LinkedIn and Facebook) that provide self-directed learning opportunities resulting in performance support (Boileau, 2011). Self-directed learning (SDL) appeared within the discipline of adult learning, or andragogy, during the 1960s, and it has developed rapidly since then (Karakas \& Manisaligil, 2012). Nearly 50 years ago, Knowles (1968) offered "a new label and a new technology" (p. 351) of adult learning to distinguish it from childhood learning. The idea of andragogy, defined as "the art and science of helping 
adults learn" (Knowles, 1980, p. 43), was differentiated from pedagogy, the art and science of helping children learn. There are various definitions of SDL in the literature. However, Knowles's (1980) theory of andragogy and his idea of the self-directed learner in part undergirds this paper. Therefore, this paper primarily defines SDL as:

A process in which individuals take the initiative, with or without the help of others, in diagnosing their learning needs, formulating learning goals, identifying human and material resources for learning, choosing and implementing appropriate learning strategies, and evaluating learning outcomes. (p. 18)

While SDL typically happens outside classrooms and training programs, it can and should be jump-started, encouraged, systematized, and enhanced by human resource development professionals (McGuire, 2014).

\section{Human Resource Development}

Human resource development (HRD) is a process for developing and unleashing human expertise (McGuire, 2014; Werner \& DeSimone, 2012). Learning, including SDL, is at the core of all HRD efforts. A major focus is on selfdirected workplace learning and performance (Werner \& DeSimone, 2012). For purposes of this paper, HRD is defined as a set of systematic and planned activities designed by an organization to provide its members with opportunities to learn necessary skills to meet current and future job demands. HRD seeks to develop people's "knowledge, expertise, productivity, and satisfaction, whether for personal or group/team gain, or for the benefit of an organization" (p. 322).

HRD professionals are concerned with facilitating organizational learning, job performance, and change through organized interventions, initiatives, and management actions for the purpose of enhancing an organization's performance capacity, capability, competitive readiness, and renewal (Werner \& DeSimone, 2012). Job performance is generally defined as the achievement of an expected or predetermined outcome (Boileau, 2011). HRD professionals must discover and adopt processes and procedures to increase workforce productivity and organizational competitiveness and profitability. In most cases, the professional skills and knowledge required by both the employee and the organization cannot be effectively learned through formal settings (Bernardez, 2012). Instead, SDL activities need to be developed and enhanced (Leslie, Aring, \& Brand, n.d.). The environment in which SDL takes place is often the same one in which the work is performed (Boileau, 2011). As a result, measurement of performance is correspondingly tied to the setting and a transfer of activities to achieve a predetermined goal. The implication is that SDL is critical to an organization's overall effectiveness and its ability to compete, and competitiveness of organizations cannot be achieved without managing performance and, at the same time, developing the skills and competence of employees (Adhikari, 2010). Performance management should, therefore, include the valuable knowledge of employees gained through SDL experiences that are supported by Web 2.0 technologies.

This paper will explore related studies, SDL and job performance needs supported by the use of Web 2.0 technology, Factors used to identify Web 2.0 technology for use at the individual level to enable SDL tied to specific job performance outcomes, Environmental factors affecting an employee's ability to use Web 2.0 technology to engage in SDL, and determination of job performance outcomes resulting from Web 2.0 enhanced SDL opportunities.

\section{RELATED STUDIES}

Perhaps the most influential existing study relative to the focus of this paper is Boileau's (2011) analysis of the role of interactive technology in informal learning and performance in a social setting. Boileau (2011) used a qualitative multiple case research study to explore participants' perceptions and behavioral intentions related to interactive technology as a mediator for informal learning and performance activities in a professional work setting. The research setting for the study was a Canadian-based publicly traded company with operations and employees located worldwide. Of a sample of 30 employees within the same company, 25 participated in this research study from two office locations situated in different major U.S. Midwestern cities. In-depth interviews were also conducted. Boileau found that interactive technology tools to enable social learning and collaboration are being adopted by employees on their initiative, rather than waiting for them to become available through the company.

Boileau (2011) also found that learning organizations in all business sectors are embracing social media to enable social learning. According to Boileau, "Social media allows individuals and organizations to embrace the needs of 
changing workplace demographics and enables people of all ages to learn in ways that are comfortable and convenient for them" (p. 151).

\section{SDL AND JOB PERFORMANCE NEEDS SUPPORTED BY THE USE OF WEB 2.0 TECHNOLOGIES}

Systematic research that focuses specifically on Web 2.0-based informal learning in the workplace remains novel and sparse (Chiu, Tsai, \& Fan Chiang, 2013). The recent study of Valencia-García, García-Sánchez, Casado-Lumbreras, Castellanos-Nieves, and Fernández-Breis (2012) attempted to develop a semantic platform for companies and users to gather useful information and conduct expertise mining from social web content such as blog posts (Zhao \& Kemp, 2013). In this qualitative study, Valencia-García et al. (2012) interviewed ten employees within the same company at a shared location and found that social web content is a useful source for knowledge sharing throughout the company. Milovanovic, Minović, Štavljanin, Savković, and Starčević (2012) investigated how to use a wiki as a tool for corporate exchange of knowledge through a case study of a software development company involving 12 participants. The study found that a wiki did facilitate informal learning and was a useful informal tool for the employees in the company to share knowledge and learn from each other during the process of software development (Zhao \& Kemp, 2013).

Littlejohn, Milligan, and Margaryan (2012), in their qualitative study of seven participants on self-regulated learning, demonstrated improved effectiveness in work-based learning where knowledge was created in a global online social network. Similarly, Hart (2012) observed in a quantitative study of 147 participants that many workers are using social networking tools to address their learning and performance needs in the workplace. These workers share a great deal in common regarding motivations and learning behavior (Zhao \& Kemp, 2013). They constantly strive to improve their productivity and solve workplace problems through asking questions, and sharing ideas with friends and colleagues in their online social networks.

These studies provide empirical evidence on SDL and job-performance needs supported by the use of Web 2.0 technologies. Moreover, findings from these studies exemplify Knowles's (1980) assumption that there is a change in time perspective as people mature - from future application of knowledge to immediacy of application. Thus, an adult is more problem-centered than subject centered in learning. The workers in these studies created knowledge in a global Web 2.0 social network. They used a wiki to facilitate informal learning and found it was a useful Web 2.0 tool for the employees in the company to share knowledge and learn from each other. They also used Web 2.0 social networking tools to address their own learning and performance needs in the workplace, constantly striving to improve their productivity and solve workplace problems through asking questions and sharing ideas with friends and colleagues in their online Web 2.0 social networks (Chiu et al. 2013; Hart, 2012; Littlejohn et al. 2012; Milovanovic et al. 2012; Valencia-García et al. 2012; Zhao \& Kemp, 2013). Adult learners seek immediacy of application (Knowles, 1980). Web 2.0 technologies allow adult learners to access information, interact with others, and share knowledge at the speed of their connectivity (Zepeda, 2015). Adult learners have a need for immediacy and application, and Web 2.0 technologies can provide for these two conditions (Hanley, 2009).

\section{FACTORS USED TO IDENTIFY WEB 2.0 TECHNOLOGIES FOR USE AT THE INDIVIDUAL LEVEL TO ENABLE SDL TIED TO SPECIFIC JOB PERFORMANCE OUTCOMES}

The majority of studies seem to focus on the context of use of the Web 2.0 tools as opposed to how and why the Web 2.0 tools were implemented (Baxter \& Connolly, 2014). For example, Holtzblatt, Damianos, and Weiss (2010) assumed an investigative study to explore whether wikis could be applied effectively to support SDL within a nonprofit organization. Employing the use of unstructured and open-ended interviews, the study uncovered various factors that prohibit the usage of wikis for SDL, namely, a reluctance to share information on the wikis among colleagues because of issues of information sensitivity, an unwillingness to share work that is unfinished, and concerns about the openness of information on the wikis (Baxter \& Connolly, 2014). The study also concluded that to ensure successful adoption of wikis, organizations should consider factors such as incentive structures to entice staff to use the wikis in addition to authoring clearer guidelines and policies defining the scope and use of the wikis.

Nyaude (2008) “examined the impact of Gilbert's (2007) Behavior Engineering Model (BEM) variable on employee perception of motivation" (p. iii). Surveys (200) were distributed to hourly employees at an aerospace equipment 
manufacturing plant in Georgia. A survey return rate of 39\% was achieved. Nyaude (2008) stated, "Knowledge and skills were perceived as highly motivating, followed by capacity, resources, information, motives and lastly incentive" (p. 86). Nyaude (2008) confirmed research findings by Swanson and Holton (2001). Swanson and Holton (2001) suggested, "Work is meaningful, workers are motivated by meaningful goals and participation and those workers should be increasingly self-directed and this self-control will improve efficiency and work satisfaction" (p. 48). Nyaude (2008) concluded that the aerospace equipment manufacturing plant would benefit from implementing the recommendations from this study of building organizational growth by motivated employees who are knowledgeable, skilled, with the capacity to produce results for the business and abundant supply of resources.

Another empirical study conducted by Stocker and Tochtermann involved a multiple-case study in three Austrian organizations that were using wikis to support the process of intraorganizational knowledge transfer (Baxter \& Connolly, 2014). Through conducting interviews and issuing surveys, the majority of employees in the respective organizations considered that the wikis were beneficial for the dissemination and accessing of knowledge. In most organizations, the flow of communication moves downward, or via a top-down approach-from someone of higher authority to someone of lower authority (Ober, 2009). Upward, or bottom-up communication is the flow of information from lower-level employees to upper-level employees. One interesting point of note derived from the research was that although all three wikis investigated in the studies were implemented via a top-down approach, the content created on the wikis mostly occurred from the bottom (Baxter \& Connolly, 2014). This finding exemplified SDL as a type of employee development where employees were given an opportunity to be heard.

A qualitative study completed by Grudin and Poole (2010) explored factors associated with successful wiki deployment in three large organizations. Through the use of interviews, the study identified common themes in relation to wiki adoption, namely, that there can be on occasion different expectations from management and staff as to what their visions are on how a wiki should be best applied in the workplace, conflict among staff members on how content is organized on wikis, and how to introduce wikis into the workplace against potential barriers of an existing information ecology and corporate culture (Baxter \& Connolly, 2014). In contrast, an exploratory study conducted by Mansour, Abusalah, and Askenas (2011) discovered factors that impacted the use of a wiki as a tool for sharing knowledge gained from informal learning and aiding in its collaboration within communities in organizations.

The research occurred in a large multinational contracting organization, consisting of employees who were regularly engaged in SDL projects (Baxter \& Connolly, 2014). The wiki employed by the organization consisted of five distinct communities of practice. Findings of the study revealed that the majority of the users of the wiki found it to be beneficial for collectively formulating and disseminating knowledge. However, a salient finding of the study was the openness of the wiki served to have a dual impact on staff members' attitudes and perceptions toward using the wiki in the workplace. For example, in addition to the wiki serving as a beneficial knowledge management tool among the communities of practice, some staff members lacked confidence in sharing their knowledge acquired through SDL activities to a wider audience in addition to accepting criticism or comments from colleagues regarding their contributions. Furthermore, certain staff members were not comfortable to comment on contributions made by senior management on the wiki.

Another Web 2.0 tool that is gaining measured recognition as a medium for supporting the process of internal communication and knowledge sharing in organizations is blogs (Baxter \& Connolly, 2013). Empirical research into the internal uses of blogs within organizations is an area that requires further investigation (Lockwood \& Dennis, 2008). However, research into organizational blog use is slowly increasing (Baxter \& Connolly, 2014). For example, an empirical study conducted by Stocker and Tochtermann (2008) assessed the use of an internal corporate blog to share knowledge gained from SDL. The study explored the use of an internal blog by the manager of the organization to disseminate knowledge to staff members (Baxter \& Connolly, 2014). Utilizing surveys, the study revealed that communicating the benefits of a blog in an organization is an important prerequisite for its success; employees in an organization will use a blog if the content included on it is relevant to their work, and blogs will be used more by employees if they cannot obtain relevant knowledge from other types of communication channels.

These studies provide empirical and qualitative evidence on factors used to identify Web 2.0 technologies for use at the individual level to enable SDL tied to specific job performance outcomes. Furthermore, findings from these studies exemplify Knowles's (1980) assumption that the readiness of an adult to learn is closely related to the development 
tasks of his or her social role. There are various factors that prohibit the use of Web 2.0 technology for SDL, factors that entice use of Web 2.0 technology, factors associated with successful Web 2.0 deployment, and evidence that employees in an organization will use Web 2.0 technology if the content is relevant to their work and social roles (Baxter \& Connolly, 2014; Grudin \& Poole, 2010; Holtzblatt et al., 2010; Lockwood \& Dennis, 2008; Mansour et al., 2011; Stocker \& Tochtermann, 2008).

\section{ENVIRONMENTAL FACTORS AFFECTING AN EMPLOYEE'S ABILITY TO USE WEB 2.0 TECHNOLOGIES TO ENGAGE IN SDL}

In a different study, Kosonen, Henttonen, and Ellonen (2007) assessed the use of blogs for internal communication in a large engineering organization and investigated factors that might have an impact on the use of internal blogs in corporate environments for SDL. In relation to the issue of introducing blogs in organizations, the study identified that the factors of corporate climate and culture affect the successful implementation of blogs (Baxter \& Connolly, 2014). A study conducted by Stieglitz and Dang-Xuan (2011) indicated that the benefits of using a wiki were not initially evident to staff who had a preference for using more familiar and accustomed types of media in their organization for obtaining knowledge through SDL activities. In comparison, Stocker and Tochhtermann's (2008) blog study revealed the importance of communicating the benefits of using Web 2.0 tools in the workplace to staff that has never been exposed to them. The barrier of staffs' apparent unwillingness to share information among colleagues by contributing content on a Web 2.0 tool was a theme found in the studies performed by Holtzblatt et al. (2010) and Mansour et al. (2011). In fact, it was the openness of the technology, in this case wikis, that contributed to staff possessing a lack of confidence in sharing knowledge gained through SDL to a wider audience in the workplace (Baxter \& Connolly, 2014). In addition to communicating the benefits of using Web 2.0 tools to staff, it is important that management ensure that there is adequate infrastructural support (Stieglitz \& Dang-Xuan, 2011) to ease adoption and to reflect on their existing corporate climate and culture (Grudin \& Poole, 2010; Kosonen et al., 2007) to assess whether the use of Web 2.0 technologies are an appropriate fit with the mission statements of their organization. To encourage staff to engage with Web 2.0 technologies at work, it is important that incentive mechanisms and guideline policies are put in place (Holtzblatt et al., 2010) and that everyone in the organization has a shared vision in relation to how the technology will be used (Grudin \& Poole, 2010; Skeels \& Grudin, 2009) otherwise adoption and continued use will not prove to be successful.

In Dean and Ripley's (1997) book, Performance Improvement Pathfinders, they describe introducing Gilbert's BEM as part of an experiential group activity called, "Where's my biggest performance block?" (p. 52). This activity provided staff with a direct opportunity to identify what area would have the greatest benefit to their performance (Russell, 2010). Dean and Ripley (1997) stated with "so many participants identifying environmental influences as needing improvement for them to do their jobs" (p. 54) better validates Gilbert's premise that performance improvement can be achieved by addressing the environmental support factors alone. With accurate information, the manager can further evaluate the barrier to determine an applicable intervention (Russell, 2010). The BEM as a troubleshooting tool opens the manager's mind to explore the possibilities of what factors are causing barriers to performance through a systematic approach. With accurate information, managers can provide the most appropriate coaching to their staff. When managers can isolate the barrier and create a specific intervention that removes the barrier with the least cost and improves performance, their employees will be more likely to be exemplary performers.

These studies provide empirical and qualitative evidence on environmental factors affecting an employee's ability to use Web 2.0 technologies to engage in SDL. Also exemplified are Knowles's (1980) assumptions of experience, readiness to learn, and orientation to learning. Adult learners in these studies were unfamiliar with or had no experience with the Web 2.0 technology and, therefore, had no reservoir of experience with its use. Readiness to learn is closely related to the development tasks of the adult learners' social roles, but in these studies, there existed an unwillingness to share information among colleagues by contributing content on a Web 2.0 tool, perhaps because of the organizational culture (Baxter \& Connolly, 2014). Further, the organizations in these studies failed to demonstrate an immediacy of application for the Web 2.0 tool (Grudin \& Poole, 2010; Skeels \& Grudin, 2009) to appeal to the problem-centered rather than subject-centered learning of the adults in the study. 


\section{DETERMINATION OF JOB PERFORMANCE OUTCOMES RESULTING FROM WEB 2.0 ENHANCED SDL OPPORTUNITIES}

Research conducted by Zhao and Kemp (2013) concluded that self-directed workplace learning is shared, context-or task-based, organizationally goal-oriented and organizationally culture-bound, and contributes to and is influenced by organizational learning. Workplace SDL gained through connections and collaborations mediated by Web 2.0 applications were examined, and Zhao and Kemp (2013) concluded that SDL is largely neither institutionalized nor controlled by institutions. Zhao and Kemp (2013) defined Web 2.0-based workplace learning as SDL that takes place in the workplace through connections and collaborations mediated by Web 2.0 technology and hypothesized Web 2.0-based self-directed informal workplace learning as the dependent variable that may be measured in various ways. For example, Zhao and Kemp (2013) quantified the variable by measuring the knowledge gained and shared informally, using Web 2.0 platforms that are relevant to jobs and duties, and to the whole workplace. The improvement in job performance through such knowledge exchange and learning can be another measure of the dependent variable.

Five independent variables were proposed by Zhao and Kemp (2013) in relation to Web 2.0-based workplace learning. According to research conducted by Zhao and Kemp, Self-interest may be measured by perceived benefits from participating in Web 2.0-based workplace learning, such as a boost in reputation, respect, status, social acceptance, and recognition. Self-fulfillment is driven largely by intrinsic motivations, which may be measured by the level of aspiration to take up new challenges and help others. Sense of belonging may be measured by how much one views oneself as part of a team or community and is willing to contribute to it. Trust, as a relational dimension of social capital, may be measured by the extent of trust one has toward other members of a network in deciding to share knowledge with them. Perceived expertise may be measured by one's perception of the extent of mastery in specialized knowledge and practices.

Research by Zhao and Kemp (2013) found that the mediating variable of Web 2.0 technology may be measured by the level of involvement with the technology in terms of the formation of, and participation in, Web-based communities and hosted services, such as social-networking sites (i.e., LinkedIn and Facebook); video sharing sites (i.e., YouTube); wikis; blogs; performance support tools; performance support systems; search engines such as Bing, Yahoo, and Google; the hardware that supports this technology, including, but not limited to desktop, laptop, or handheld computers, web cams, smartphones, and tablets; and the use of applications (apps), which are accessed from mobile devices. Zhao and Kemp (2013) concluded their research by stating, "Organizational support, as a moderator, may be measured in terms of the level of investment in Web 2.0 technologies, providing on-going technical support and training, as well as taking initiatives in nurturing an organizational learning culture" (p. 13).

These studies provide empirical and qualitative evidence of job-performance outcomes resulting from Web 2.0 enhanced SDL opportunities.

\section{CONCLUSION}

Web 2.0 technologies have been shown to have a mediating effect on activity through the use of symbols for linguistic communication and artifacts for externally managed collective knowledge (Boileau, 2011). Rossett and Schafer (2007) view this effect in terms of performance support, as a repository for information, processes, and perspectives that inform and guide planning and action. Relevance ensures support, enabling a self-directed learner to accomplish his or her goals in a specific context, and personalization adjusts information and guidance according to a set of individualized needs in a specific context (Rossett \& Schafer, 2007). A study conducted by Milovanovic et al. (2012) found that a wiki did facilitate informal learning and was a useful informal tool for the employees in the company to share knowledge and learn from each other during the process of software development. The wiki analyzed in the study conducted by Milovanovic et al. (2012) is comparable to the company database described by the participants in this study. The majority of studies seem to focus on the context of use of the Web 2.0 tools as opposed to how and why the Web 2.0 tools were implemented (Baxter \& Connolly, 2014). For example, Holtzblatt et al. (2010) assumed an investigative study to explore whether wikis could be applied effectively to support SDL within a nonprofit organization. Employing unstructured and open-ended interviews the study uncovered various factors that prohibit the usage of wikis for SDL namely a reluctance to share information on the wikis among colleagues because of issues of information sensitivity, an unwillingness to share work that is unfinished, and concerns about the openness of 
information on the wikis (Baxter \& Connolly, 2014). The study also concluded that to ensure successful adoption of wikis, organizations should consider factors such as incentive structures to entice staff to use the wikis in addition to authoring clearer guidelines and policies defining the wikis' scope and use.

\section{Identify Web 2.0 Technology}

It has been established through this paper that Web 2.0 technologies must be situated in the work environment to facilitate SDL experiences resulting in job performance. A recommendation for this finding is that organizations identify the Web 2.0 tools they feel are most beneficial to the organization and endorse them as workplace friendly learning resources. If employees know that Google is considered a work-friendly workplace tool, for example, but LinkedIn or Facebook is not, then employees have guidelines for their SDL choices.

\section{Build A Code of Conduct with Employees}

Boileau (2011) found that interactive technology tools to enable social learning and collaboration are being adopted by employees on their initiative, rather than waiting for them to become available through the company. It is recommended that organizations work in collaboration with employees to define how Web 2.0 technology can and should be used in the workplace for SDL purposes. The collaboration process may be enhanced by incorporating learning teams, employees, and management into the collaboration process to establish what rules should be in place, and what consequences for any infringements should be. Organizations should also find out from employees how Web 2.0 technologies are enhancing their productivity. The goal here is to encourage more SDL and job-performance outcomes resulting from the use of Web 2.0 technology while maintaining focus and security integrity.

\section{Create Internal Collaboration}

Web 2.0 technologies must be informative, intuitive, situated in the work environment, and consequences for poor performance must be removed to facilitate SDL experiences resulting in job performance. In the interest of supporting the performance of employees, many organizations employ strategies that attempt to extend key messages and create mantras to influence more effectively learning and performance. Through print and online materials, such as job aids or performance support, documentation and help systems, organizations, along with their HRD professional counterparts can break the physical and temporal boundaries associated with training experiences (Bernardez, 2012; Rossett \& Sheldon, 2001). Some circumstances merit the use of information support rather than training. These approaches should be pursued when a task is performed infrequently; when it involves many steps and decisions; when the consequences of making a mistake would be grave; when knowledge is changing, vast, and complex; and when resources are tight. Boileau (2011) found that learning organizations in all business sectors are embracing social media to enable social learning. According to Boileau, "Social media allows individuals and organizations to embrace the needs of changing workplace demographics and enables people of all ages to learn in ways that are comfortable and convenient for them" (p. 151).

Organizations should create internal collaboration and Web 2.0 technology that encourages information and knowledge sharing while minimizing security and confidentiality risks. Web 2.0 technologies should be aligned with the organization's industry to guide employees to the resources that offer the most learning potential.

\section{Communicate Expectations of Adequate Performance}

Expected performance and adequacy of performance are environmental factors affecting behavioral intentions toward the use of Web 2.0 technologies. Organizations should begin the process of expectations for the use of and proficiency with Web 2.0 technology by explicitly communicating those expectations to employees. Employees should be given of list of Web 2.0 technologies that the organization uses and reasons for using each. It may not be enough for an organization to identify, implement, and communicate expectations of adequate performance for Web 2.0 technologies. Organizations need to be sure their employees adopt the technology and use it. Web 2.0 technology should require minimal training and guide the employee to the desired performance outcome. Technology changes rapidly, and more and more tools are being introduced. Employees need to see the benefit of newly introduced Web 2.0 technologies because they may resist the change and continue performing tasks in a method that is more familiar 
to them, especially if employees fail to see the immediacy of application in how the new technology solves problems. Involving employees in the change that new Web 2.0 technology brings about will help them realize the problemsolving applications of the new technology and allow organizations to promote early successes with it. Communicated in this way, employees realize the value of the technology to the company as well as to themselves.

\section{Recommendations for HRD Professionals}

To keep up with the rapid changes in Web 2.0 technology, HRD professionals need to (a) determine barriers that are preventing employees from accessing the tools that could enhance their SDL and job performance outcomes, (b) make available to employees Web 2.0 technologies that connect SDL with job performance, and (c) encourage employees to learn continuously using mobile and digital tools. To enable the integration of Web 2.0 technology into a blended learning site, HRD professionals can provide employees with a myriad of learning options, such as workshops, seminars, and even webinars that offer employees the opportunity to tailor their learning according to their performance needs. To cultivate SDL facilitated by Web 2.0 technologies, organizations should provide adequate time, opportunities, resources, and incentives to develop competencies in using Web 2.0 technologies to solve problems and perform tasks.

Employees may face challenges if they do not receive guidance in using Web 2.0 technologies. SDL facilitated by Web 2.0 technologies requires a set of skills for effective implementation. These skills include literacy with using Web 2.0 technology, time management, self-evaluation of learning outcomes, and the ability to work independently. HRD professionals should be responsible for guiding and training employees to support their learning experiences. Employees face some challenges such as retrieving misleading information or information that lacks credibility. HRD professionals should play a critical role supporting and mentoring employees to uncover and work together to alleviate these challenges.

\section{AUTHOR BIOGRAPHY}

Shirley J. Caruso, Ed.D. is an instructor and undergraduate advisor in the Human Resource Development (HRD) Program at Northeastern Illinois University, Chicago, Illinois, and a training and development consultant in the Chicago area. She puts HRD theories into practice by supporting the learning goals of students, focusing on student learning outcomes, developing talented employees to help clients achieve real competitive advantages, designing and delivering highly effective training and development programs that enable participants to enhance their individual performance, and working in collaboration with faculty to promote educational innovation and the improvement of student learning.

\section{REFERENCES}

Adhikari, D. R. (2010). Human resource development (HRD) for performance management. International Journal of Productivity and Performance Management, 59(4), 306-324. doi:10.1108/17410401011038883

Baxter, G. J., \& Connolly, T. M. (2013). The 'state of art' of organisational blogging. The Learning Organization, 20(2), 104117.

Baxter, G. J., \& Connolly, T. M. (2014). Implementing web 2.0 tools in organisations: Feasibility of a systematic approach. The Learning Organization, 21(1), 6-25. doi:10.1108/TLO-11-2012-0069

Bernardez, M. L. (2012). Surviving performance improvement "solutions": Aligning performance improvement interventions. Performance Improvement Quarterly, 22(2), 111-127. Retrieved from ProQuest Education Journals. (218565741)

Boileau, T. (2011). The effect of interactive technology on informal learning and performance in a social setting. Available from ProQuest Dissertations \& Theses Global. (UMI No. 3479477)

Chiu, Y. L., Tsai, C. C., \& Fan Chiang, C. Y. (2013). The relationships among nurses' job characteristics and attitudes toward web-based continuing learning. Nurse Education Today, 13(4), 327-333.

Dean, P. J., \& Ripley, D. E. (Eds.). (1997). Performance improvement pathfinders. Washington, DC: The International Society for Performance Improvement.

Gilbert, T. F. (2007). Human competence engineering worthy performance (Tribute ed.). San Francisco, CA: Pfeiffer.

Grudin, J., \& Poole, E. S. (2010). Proceedings of the $6^{\text {th }}$ International Symposium on Wikis and Open Collaboration: New Wikis at work: Success factors and challenges for sustainability of enterprise wikis. York: ACM Press.

Hanley, M. (2009). Are you ready for informal learning? Information Outlook, 13(7), 12-14, 16-18. 
Hart, J. (2012). Learning in the social workplace. Internet Time Alliance [online]. Retrieved from http://internettimealliance.com/wp/wp-content/uploads/2011/11/liswpwp.pdf

Holtzblatt, L. J., Damianos, L. E., \& Weiss, D. (2010). In CHI EA 10 Proceedings of the 28th of the international conference extended abstracts on Human factors in computing systems: Factors impeding wiki use in the enterprise: A case study. 4661-4675. New York, NY: ACM Press.

Karakas, F., \& Manisaligil, A. (2012). Reorienting self-directed learning for the creative digital era. European Journal of Training and Development, 36(7), 712-731. doi:10.1108/03090591211255557

Knowles, M. S. (1968). Andragogy, not pedagogy. Adult Leadership, 16(10), 350-352, 386.

Knowles, M. S. (1980). The modern practice of adult education: From pedagogy to andragogy (2 ${ }^{\text {nd }}$ ed.). New York, NY: Cambridge Books.

Kosonen, M., Henttonen, K., \& Ellonen, H. K. (2007). Weblogs and internal communication in a corporate environment: A case from the ICT industry. International Journal of Knowledge and Learning, 3(4/5), 437-449.

Leslie, B., Aring, M. K., \& Brand, B. (n.d.). Informal learning: The new frontier of employee and organizational development. Economic Development Review, 15(4), 12-18.

Littlejohn, A., Milligan, C., \& Margaryan, A. (2012). Charting collective knowledge: supporting self-regulated learning in the workplace. Journal of Workplace Learning, 24(3), 226-238.

Lockwood, N. S., \& Dennis, A. R. (2008). Proceedings of the 41st Hawaii International Conference on System Sciences: Exploring the corporate blogosphere: A taxonomy for research and practice. January 7-10, p.1-10.

Mansour, O., Abusalah, M., \& Askenas, L. (2011). Proceedings of the 5th International Conference on Communities and Technologies: Wiki-based community collaboration in organizations. C\&T'11: 29 June-2 July 2011, QUT, Brisbane, Australia, p. 79-87.

McGuire, D. (2014). Human resource development ( $2^{\text {nd }}$ ed.). Thousand Oaks, CA: Sage Publications Inc.

Milovanovic, M., Minović, M., Štavljanin, V., Savković, M., \& Starčević, D. (2012). Wiki as a corporate learning tool: Case study for software development company. Behaviour \& Information Technology, 31(8), 767-777.

Nyaude, A. (2008). Manufacturing challenge: An employee perception of the impact of BEM variables on motivation (Doctoral dissertation). Available from ProQuest Dissertations \& Theses. (AAI3311268)

Ober, S. (2009). Contemporary business communication ( $7^{\text {th }}$ ed.). Boston, MA: Houghton Mifflin Company.

Reiser, R. A., \& Dempsey, John V. (2012). Trends and issues in instructional design and technology (3 ${ }^{\text {rd }}$ ed.). Boston, MA: Allyn \& Bacon.

Rosenberg, M. J. (2013). At the moment of need: The case for performance support. Santa Rosa, CA: The eLearning Guild.

Rossett, A., \& Schafer, L. (2007). Job aids and performance support: Moving from knowledge in the classroom to knowledge everywhere. San Francisco, CA: Pfeiffer.

Rossett, A., \& Sheldon, K. (2001). Beyond the podium: Delivering training and performance to a digital world. San Francisco, CA: Jossey-Bass/Pfeiffer.

Russell, H. G. (2010). Through the use of Gilbert's behavioral engineering model: What changes can management make to increase blood donations? Retrieved from ProQuest Education Journals. (518680095)

Skeels, M. M., \& Grudin, J. (2009). When social networks cross boundaries: A case study of workplace use of Facebook and LinkedIn. GROUP '09: Proceedings of the ACM 2009 International Conference on Supporting Group Work. Sanibel Island, Florida, pp. 95-103.

Stern, J. (2015). Web 2.0 Technologies. Access Science (n.d.). Introduction to Web 2.0 Technologies. Retrieved from http://www.wlac.edu/online/documents/Web_2.0\%20v.02.pdf

Stieglitz, S., \& Dang-Xuan, L. (2011). Adoption and use of corporate wikis in German small and medium-sized enterprises. Retrieved from http://aisel.aisnet.org /amcis2011_submissions/235

Stocker, A., \& Tochtermann, K. (2008). Proceedings of 11th International Conference on Business Information Systems: Investigating weblogs in small and medium enterprises: An exploratory case study. In D. Flejter, S. Grzonkowski, T. Kaczmarek, M. Kowalkiewwicz, T. Nagle, \& J. Parkes, (Eds). (2nd Workshop on Social Aspects of the Web, 95-107.

Swanson, R. A., \& Holton, E. F. (2001). Foundations of human resource development. San Francisco, CA: Berrett-Koehler.

Valencia-García, R., García-Sánchez, F., Casado-Lumbreras, C., Castellanos-Nieves, D., \& Fernández-Breis, J. T. (2012). Informal learning through expertise mining in the social web. Behaviour \& Information Technology, 31(8), $757-766$.

Werner, J., \& DeSimone, R. (2012). Human resource development (6th ed.). Mason, OH: South-Western, Cengage Learning.

Zepeda, S. (2015). Job-embedded professional development: Support, collaboration, and learning in schools. New York, NY: Routledge.

Zhao, F., \& Kemp, L. (2013). Exploring individual, social and organizational effects on Web 2.0-workplace learning: A research agenda for a systematic approach. Research in Learning Technology. The Journal of the Association for Learning Technology (ALT), 21(1), 1-12. 
NOTES 